\title{
Correction to: Karen Bluth: The Self-Compassionate Teen: Mindfulness and Compassion Skills to Conquer Your Critical Inner Voice
}

Instant Help Books, Oakland, CA, 2020, 192 pp, ISBN 9781684035274

\section{Chris Fradkin $\mathbb{1}^{1,2}$}

Published online: 8 February 2021

๑) Springer Science+Business Media, LLC, part of Springer Nature 2021

Correction to: Journal of Youth and Adolescence (2021) https://doi.org/10.1007/s10964-020-01368-x

The original version of the article was inadvertently published with the errors in Abstract section.

The beginning sentence in abstract should read as, "Adolescence is a developmental stage filled with stress and pres- sure" instead of "Adolescence is a developmreal), who loves and accepts them exactly as theyental stage filled with stress and pressure". This has been corrected with this erratum.

The original article has been corrected.

Publisher's note Springer Nature remains neutral with regard to jurisdictional claims in published maps and institutional affiliations.
The original article can be found online at https://doi.org/10.1007/ s10964-020-01368-x.

\section{Chris Fradkin}

chrisfradkin@gmail.com

1 Universidade do Estado do Rio de Janeiro, Rio de Janeiro, Brazil

2 University of California, Merced, CA, USA 